\title{
Investigando o perfil e elementos motivacionais de plantadores de árvores em suas práticas de protagonismo ambiental
}

\author{
Investigating the profile and motivational elements of tree planters in their \\ environmental leadership practices
}

\section{Investigar el perfil y los elementos motivacionales de los plantadores de árboles en sus prácticas de protagonismo ambiental}

\author{
Fabio Gabriel Nascibem 1 \\ Alessandra Aparecida Viveiro ${ }^{2}$ \\ Oswaldo Gonçalves Junior ${ }^{3}$
}

\begin{abstract}
Resumo:
O presente artigo origina-se de pesquisa que teve por objetivo investigar práticas de protagonismo ambiental relacionadas à arborização. Dessa forma, procurou-se investigar as motivações envolvidas em práticas de arborização promovidas por atores sociais em diferentes espaços. Foram utilizadas a etnografia de rede social e histórias orais, sendo os critérios de análise emersos desse processo. Os atores sociais foram identificados por meio de reportagens da grande mídia, em uma comunidade no Facebook, denominada "Plantadores de Árvores", e também por meio de indicações, sendo selecionados para entrevistas plantadores residentes em pequena, média e grande mancha urbana. Ha' indícios, de acordo com os principais resultados, que haja relação entre a motivação central dos plantadores e sua causa de plantar com a temática do pertencimento e que o entendimento das relações entre saberes e fazeres parece ser importante neste processo. Tais apontamentos sinalizam que a pluralidade de saberes, fazeres, culturas e ópticas estão presentes, abrindo espaço para discussão sobre uma racionalidade ambiental envolvida.
\end{abstract}

Palavras-chave: Arborização; Motivação; Protagonismo ambiental.

\begin{abstract}
:
This paper derives from research that aimed to investigate environmental protagonism practices related to tree planting. Thus, we sought to investigate the motivations involved in this practices promoted by social actors in different spaces. Social network ethnography and oral histories were used, and the criteria for analysis were based on this process. The social actors were identified through news from mass media, in a community on Facebook, called "Tree Planters", and also through indications, being selected to interviews residents in small, medium and large urban spot. There are indications, according to the main results, that there is a relationship between the central motivation of planters and their cause of planting with the theme of belonging and that the understanding of the relations between knowledge and doing seems to be important in this process. These notes indicate that the plurality of knowledge, actions, cultures and optics are present, making room for discussion about an

1 Universidade Estadual de Campinas, Programa de Pós-graduação Multiunidades em Ensino de Ciências e Matemática. Campinas, SP, Brasil.

2 Universidade Estadual de Campinas, Faculdade de Educação. Campinas, SP, Brasil.

3 Universidade Estadual de Campinas, Faculdade de Ciências Aplicadas. Limeira, SP, Brasil.
\end{abstract}


environmental rationality involved.

Keywords: Tree planting; Motivation; Environmental protagonism.

\section{Resumen:}

Este artículo se origina en una investigación que tuvo como objetivo investigar las principales prácticas ambientales relacionadas con la plantación de árboles. Por lo tanto, buscamos investigar las motivaciones involucradas en estas prácticas promovidas por actores sociales en diferentes espacios. Se usaron etnografía de redes sociales e historias orales, y los criterios para el análisis se basaron en este proceso. Los actores sociales fueron identificados a través de informes de los medios de comunicación, en una comunidad de Facebook llamada "Plantadores de árboles", y también a través de avisos, siendo seleccionados para entrevistas con residentes de plantación en pequeñas, medianas y grandes ubicaciones urbanas. Según los resultados principales, hay indicios de que existe una relación entre la motivación central de los plantadores y su causa de siembra con el tema de pertenencia y que la comprensión de la relación entre el conocimiento y el hacer parece ser importante en este proceso. Estas notas indican que la pluralidad de conocimientos, acciones, culturas y perspectivas están presentes, lo que lleva a una discusión sobre una racionalidad ambiental involucrada.

Palabras clave: Plantación de árboles; Motivación; Liderazgo ambiental.

\section{Introdução}

O colapso ambiental que se avizinha é produto de um modelo de sociedade. Este modelo carrega em si uma série de valores que hierarquizam seres humanos e natureza. Colocam à frente a acumulação de bens e capital para além de uma necessidade real, gerando consumismo, enorme concentração e consequente desigualdade entre os habitantes do Planeta. $O$ individualismo se destaca como um valor central. Apesar disso, pode-se dizer que uma dicotomia marca o comportamento dos seres humanos, pois o altruísmo ainda resiste, assim como existem iniciativas visando o bem comum.

Leff (2010) reconhece que estamos vivendo um período demarcado por uma crise epistemológica. De um lado, a lógica instrumental do capitalismo; de outro, a emergência de uma nova racionalidade, pautada no diálogo de saberes, na interdisciplinaridade, na complexidade. De acordo com Leff (2010, p. 318), o conflito ambiental

... está marcado por interesses pela apropriação da natureza como fonte de riqueza e suporte de práticas produtivas. Nesses processos, os conhecimentos e os saberes jogam um papel instrumental ao potenciar a apropriação econômica da natureza; mas também jogam como saberes que forjam sentidos e que mobilizam a ação com valores não mercantis e para fins não materiais nem utilitários.

Para o autor,

A crise ambiental e a crise do saber surgem como a acumulação de "externalidades" do desenvolvimento do conhecimento e do crescimento econômico. Surgem como todo um campo do real negado e do saber 
desconhecido pela modernidade, reclamando a "internalização de uma "dimensão ambiental" através de um "método interdisciplinar", capaz de reintegrar o conhecimento para apreender a realidade complexa (LEFF, 2011, p. 309).

Em Leff (2009a, b, 2010a, b, 2011, 2015), os saberes e fazeres populares têm um papel central na construção de uma nova racionalidade, sendo que não é possível superar a crise ambiental com visões hegemônicas científicas atreladas ao interesse do capital, desprezando as necessidades e as determinações sociais e populares.

Leff (2010) propõe que se faça uma hibridização radical entre os saberes. Em outras palavras, que todos os saberes sejam postos em diálogo, gerando um grande saber híbrido, que dê conta da complexidade e pluralidade do mundo. Para o autor, o olhar para o diálogo entre saberes é central na constituição daquilo que chama de racionalidade ambiental, para além da racionalidade do capital.

\begin{abstract}
O diálogo de saberes não é um relaxamento do regime disciplinar na ordem do conhecimento para dar lugar à aliança de lógicas contraditórias, a abertura de um jogo indiferente de linguagens, a um consumo massificado de conhecimentos, ou de uma personalização subjetiva e individualizada do conhecimento, capazes de coabitar com suas contradições. O saber ambiental se forja no encontro (enfrentamento, entrecruzamento, hibridização, antagonismo) de saberes diferenciados por matrizes de racionalidade-identidade-sentido que respondem a estratégias de poder pela apropriação do mundo e da natureza (LEFF, 2010, p. 331).
\end{abstract}

É por excelência o encontro com as diferentes identidades presentes no planeta, cada qual com suas práticas e costumes, para muito além da visão do mercado, "mobilizando os atores sociais para a construção de estratégias alternativas de reapropriação da natureza em um campo conflitivo de poder, no qual se desdobram sentidos diferenciados e, muitas vezes, antagônicos, na construção de um futuro sustentável" (LEFF, 2009b, p. 19).

É a partir desse contexto mais amplo que tomamos um foco de estudo. Lançamos um olhar sobre atores sociais que mobilizam ações de protagonismo ambiental em práticas de arborização, plantando árvores em espaços públicos e privados, seja no quintal ou calçada de suas casas, à beira de córregos, em canteiros de ruas e avenidas, praças e parques etc. Interessa caracterizar essas práticas, estudando as motivações, saberes e fazeres a elas relacionados, tema que já vinha sendo explorado em trabalhos anteriores (NASCIBEM, 2019; NASCIBEM; VIVEIRO; GONÇALVES JUNIOR, 2017; VIVEIRO; GONÇALVES JUNIOR, 2016-2017). Espera-se, a partir disso, compreender esse movimento e buscar indícios sobre a racionalidade envolvida nesses processos. A questão da racionalidade se vincula ao questionamento: práticas de protagonismo ambiental relacionadas à arborização podem sinalizar um movimento dentro de uma racionalidade ambiental?

A racionalidade ambiental perpassa por identificar questões relacionadas a habitat, conexão com a natureza e pertencimento. Leff (2009) argumenta que o senso de pertencimento das pessoas em relação ao local aumenta quando tem suas culturas e saberes respeitados, fazendo com que se sintam parte daquele todo. 
Consiste em um saber que faz parte do ser, na articulação do real complexo e do pensamento complexo, no entrecruzamento dos tempos e na reconstituição das identidades. O saber ambiental se inscreve no terreno do poder que atravessa todo saber, do ser que sustenta todo saber e do saber que configura toda identidade. O saber ambiental constrói estratégias de reapropriação do mundo e da natureza (LEFF, 2009b, p. 21).

Segundo o autor, "o ser, diverso por sua cultura, ressignifica seu saber para dar-lhe seu selo pessoal, para inscrever seu estilo cultural e reconfigurar identidades coletivas" (LEFF, 2009b, p. 23).

Na ocasião da intensificação da globalização, identidades, saberes, fazeres, culturas e tradições foram erodidos a partir das pressões impostas por uma cultura hegemônica (LEFF, 2015). Demanda, então, além da emancipação dos saberes, ditos em uma ecologia de saberes, reforçar as identidades e valorização local. Assim como Leff (2015, p. 286), pensamos que "habitar o habitat é localizar no território um processo de reconstrução da natureza, a partir de identidades culturais diferenciadas". Habitar está muito além de apenas ocupar o espaço, é sentir-se integrante do espaço, pertencer, portanto; realizar atividades culturais a partir da apropriação do espaço (LEFF, 2015). Em outras palavras, o habitar humano está muito além do habitar biológico de qualquer outro ser: é modificar o espaço pelo exercício cultural (LEFF, 2015).

A questão de pertencimento na sociedade contemporânea é essencial, pois vivemos não raro sob um estado de angústia, frente ao esvaziamento dos sentidos existenciais (LEFF, 2010). Identidade e exercício dos saberes, suas demandas e culturas também colocadas em prática, provocando modificação cultural do habitat, podem alimentar e retroalimentar processos de revitalização deste senso de pertencimento. No âmbito deste artigo, entende-se que esse diálogo acolha reflexões sobre práticas de plantio de árvores e noções de pertencimento, de conexão e reconexão com a natureza, envolvendo saberes e fazeres, universo que se relaciona àquilo que está sendo entendido como uma racionalidade ambiental (LEFF, 2009a, b, 2010a, b, 2011, 2015).

\section{Procedimentos Metodológicos}

Realizamos uma pesquisa webgráfica, com estudo de reportagens midiáticas tratando de casos de plantadores, disponibilizadas em uma comunidade virtual do Facebook denominada "Plantadores de Árvores". Os textos foram lidos, identificando aqueles que tratavam de iniciativas individuais de plantio. Após a seleção, houve uma tentativa de levantar indícios das motivações dos plantadores em questão, a partir do que as iniciativas foram agrupadas e discutidas, conforme apresentaremos na próxima seção.

Por meio desse levantamento, identificamos alguns atores sociais de interesse para realização de entrevistas. Além desses, identificamos outros sujeitos por indicações de membros da comunidade virtual ou por se destacarem por suas práticas de plantio de árvores em algum local.

Para definir com quem faríamos contato, buscando um grupo diversificado para participar da pesquisa, estabelecemos alguns critérios para selecionar os possíveis colaboradores.

O primeiro deles foi relacionado ao local de moradia dos plantadores. Procuramos identificar plantadores que se destacavam pela sua prática em uma cidade de pequeno porte (até 50 mil habitantes), 
uma de médio porte (até 250 mil habitantes) e em regiões metropolitanas. A intenção, neste caso, foi a de tentar perceber se os elementos motivacionais, saberes e fazeres se alteravam de acordo com o tamanho da cidade. Um outro critério foi a questão da idade. Buscamos trabalhar com jovens, adultos e idosos. Após contato, conseguimos realizar entrevistas com seis plantadores. Trabalhamos tendo como base a História Oral Temática, conforme descreve Alberti (2004) e Garnica (2011).

O processo de construção dos depoimentos se iniciou com conversações prévias antes das entrevistas com os colaboradores, para que pudéssemos emergir nas suas biografias. Construímos um roteiro geral levando em conta o nosso referencial, nosso problema de pesquisa e objetivo. A partir das conversações prévias, os roteiros foram adaptados caso à caso. No caso dos plantadores com mais de 60 anos, as entrevistas ocorreram no local da moradia ou trabalho, de acordo com a escolha do colaborador. As entrevistas com os colaboradores com idade inferior a 60 anos ocorreram utilizando ferramentas digitais de comunicação síncrona, de modo online, também por escolha dos colaboradores.

As entrevistas foram transcritas e, posteriormente, fizemos a textualização como uma forma de narrativa de cada plantador, constituindo uma coletânea de depoimentos. O material foi analisado e, neste artigo, apresentamos sínteses a partir de alguns aspectos: caracterização dos plantadores e a motivação para o plantio, onde plantam, técnicas e saberes empregados no plantio.

\section{Levantamento webgráfico: um olhar sobre os plantadores no contexto de reportagens ${ }^{4}$}

O percurso deste levantamento webgráfico configurou a análise de plantadores individuais identificados em reportagens disponíveis na grande mídia. Para iniciar a análise, em um universo de cerca de 200 reportagens, selecionamos 15, envolvendo aquelas que tratavam de experiências individuais de plantadores.

Este levantamento ensejou emergir dois grandes eixos que enquadram os atores quanto ao motivo principal disparador de suas ações de protagonismo ambiental. São eles:

a) Saberes e fazeres tradicionais, saber científico ou técnico ou diálogo entre ambos os saberes: Os saberes tradicionais bem como os saberes científicos ou técnicos estão explicitamente citados neste eixo como disparadores do protagonismo dos atores envolvidos ou ainda há claramente um diálogo entre estes dois grandes grupos de saberes como disparador.

b) Pertencimento, sensibilização e ligação emocional: Neste eixo, os atores envolvidos explicitam seus sentimentos de quererem melhorar seus locais de vivência, melhorar a qualidade de vida e o convívio, lançando mão, para tanto, de ações de plantio. São também enquadrados nele, os atores que apontaram sensibilização pela causa ambiental em algum momento, por algum motivo; ou tiveram curiosidade em plantar e gostaram do resultado e não pararam nunca mais, e que passaram a ter uma ligação emocional com as suas ações.

Duas reportagens foram agrupadas como (c) Outras Motivações.

4 Os resultados desse levantamento webgráfico foram apresentados como parte de um artigo apresentado no X ENCONTRO PESQUISA EM EDUCAÇÃO AMBIENTAL (EPEA), que ocorreu na Universidade Federal de Sergipe, Campus São Cristóvão, Aracaju-SE, em 2019. 
No eixo (a) "Saberes e Fazeres Tradicionais, saber científico ou técnico ou diálogo entre ambos os saberes" encontramos quatro casos. O primeiro, bastante divulgado na mídia, envolve um homem que se valeu de conhecimentos antepassados para recuperar uma região desértica, adaptando-os aos tempos atuais, fazendo experimentações e melhorando o método.

Uma segunda reportagem guarda uma curiosidade que se deve ao fato da técnica de enxertia ser uma técnica milenar de cultivo, e, portanto, um conhecimento tradicional, que fora empregado por um professor universitário para produção de frutas, que, por sua vez, aproveitou-se de seu conhecimento técnico. Eis um caso clássico de simetrização e de diálogo entre saberes. As outras duas reportagens agrupam também pessoas com formação técnica que se valem de suas formações para realizar ações de protagonismo ambiental: um ecologista e educador ambiental que plantou, ao longo da vida, cerca de 500 mil árvores, e um biológo e educador ambiental que recuperou 20 mil metros quadrados de vegetação às margens de uma lagoa.

Pensamos que os saberes expressos se relacionam de acordo com os diálogos entre saberes científico e popular, fornecendo ricas visões de mundo. Em pessoas que possuem conhecimentos emaranhados, umas afloram mais um determinado saber ou outro, mas mesmo uma pessoa que tenha predominância de um pensamento científico-acadêmico, e percebe-se como agente de transformação do seu meio, é porque se reconhece como ser inserido em uma tessitura social (FLECK, 2010).

No eixo (b), "Pertencimento, sensibilização e ligação emocional", temos a maior incidência de reportagens, que são agrupadas por tratarem de temas relacionados ao sentimento de pertencer ao local e querer o melhor dele, sendo coerente com o núcleo teórico composto pelos escritos de Enrique Leff.

A primeira reportagem trata de um adolescente que planta árvores em seu apartamento e possui um grupo de voluntariado que se configura em uma rede de troca de sementes. O intuito do jovem é melhorar a convivência da cidade onde vive, tornando-a mais "verde" a partir de plantas nativas da região. Uma segunda reportagem exprime a iniciativa de uma empresária que, ao renovar votos ao findar do ano, imaginou fazer uma promessa que fosse boa não apenas para si própria, mas para todas as pessoas e, assim, passou a plantar em terrenos baldios. Em outro texto, temos um agricultor que sozinho reflorestou uma parcela da Cantareira, e se orgulha das cascatas de água que surgiram no local e fornece água para muitas pessoas. Uma quarta reportagem trata de uma pessoa que, ao sair do interior para morar na cidade de São Paulo, sente-se mal pela desconexão com a natureza e passa a plantar para tornar o ambiente cinzento mais agradável. A quinta reportagem traz o relato de um homem que se sentiu vazio após perder a esposa e encontrou razão de vida plantando árvores. Em outro texto, um ator conta que despertou a sua vontade de plantar ao ler uma citação em uma estação férrea. A sétima reportagem conta o caso de uma moça indiana que plantou árvores desde criança e, ao se casar, pediu o plantio de dez mil árvores no lugar de ouro como presente de casamento. A oitava reportagem trata da história de um pescador que começou a plantar para fazer sombra em seu local de pesca, mas se apaixonou pelo resultado e fez disso um hobby. Por último, um texto conta sobre um agricultor que se liga emocionalmente para recuperar uma região previamente degradada pela família na ocasião de terem derrubado a vegetação para exercer agricultura convencional.

Este eixo se relaciona fortemente com a concepção de pertencimento e território, onde a conjunção dos saberes e costumes locais, simbolizados pelas árvores nativas, e o sentimento de querer melhorar o ambiente onde se vive, é o eixo integrador entre estes plantadores. A questão da sensibilização e 
ligação emocional está também relacionada, de certa maneira, com noções de pertencimento, pois o sentimento de ligação com ambiente remete à ligação com a natureza. Todo arcabouço teórico discutido aponta para a direção desta interligação, em oposição à visão hegemônica da sociedade atual, referendado ao olhar as motivações expressas nas reportagens. Por sua vez, o sentimento de desligamento remete a uma visão ocidentalista e materialista, que retira os aspectos socioambientais, e enxergam a relação puramente extrativista.

Duas reportagens envolveram casos bastante diferentes entre si e dos demais antes agrupados. Uma delas relata o caso de um cidadão os Estados Unidos da América que pretendia percorrer os cinquenta estados do país plantando 50 árvores em cada localidade. Outra envolve um vereador eleito que decidiu plantar uma árvore para cada voto recebido.

Os eixos (a) e (b) estão fortemente correlacionados entre si, pois os saberes e fazeres contidos explicitamente no eixo (a) são partes integrantes da noção de pertencimento do eixo (b), tal como apontada por Leff, uma vez que as pessoas se sentem pertencidas, inseridas em uma comunidade quando se veem respeitadas quanto às suas culturas, saberes e seus fazeres, bem como tendo seu próprio espaço físico, sua casa e sua terra.

Outra questão que chama atenção é que de 15 reportagens, 13 mencionavam ações de plantadores do gênero masculino e apenas 2 do gênero feminino.

\section{As histórias de seis plantadores: motivações, saberes e fazeres}

\section{- Caracterização e motivações}

No Quadro 1 constam informações sobre idade (por ocasião da entrevista), identidade de gênero, local de nascimento e de moradia de cada um dos colaboradores dessa etapa da pesquisa. A organização dos plantadores pela indicação de 1 a 6 obedeceu a ordem das entrevistas.

Quadro 1. Caracterização dos entrevistados

\begin{tabular}{|c|c|c|c|c|}
\hline Plantador & Idade & Sexo & $\begin{array}{c}\text { Local de } \\
\text { nascimento }\end{array}$ & Local de moradia \\
\hline 1 & 22 anos & Masculino & São Carlos - SP & São Carlos - SP \\
\hline 2 & 71 anos & Masculino & Monte Alto - SP & Monte Alto - SP \\
\hline 3 & 87 anos & Masculino & $\begin{array}{c}\text { Fernando Prestes/ } \\
\text { Vista Alegre - SP }\end{array}$ & Monte Alto - SP \\
\hline 4 & 65 anos & Masculino & Tabapuã - SP & Monte Alto - SP \\
\hline 5 & 33 anos & Masculino & Sorocaba - SP & Jundiaí - SP \\
\hline 6 & 19 anos & Masculino & São Paulo - SP & Carapicuíba - SP \\
\hline
\end{tabular}

Fonte: Autores.

Todos os seis plantadores são do gênero masculino. Das histórias orais produzidas, temos que, no cerne da motivação e da inspiração ou ainda de primeiras lembranças de práticas de plantio, em muitas delas os plantadores citam espontaneamente figuras masculinas como inspiradores ou que se 
lembram de terem plantado a primeira árvore junto com pai, avô, tio, etc. Somente os colaboradores 1 e 6, mais jovens, citam figuras femininas em algum momento da sua motivação (uma avó e uma paisagista, respectivamente). Ainda assim, o plantador 1 ressalta a figura do pai nesse processo, que também é, segundo ele, um plantador. O plantador 6 atribui à paisagista citada o incentivo e as técnicas para a sua prática.

Se retomarmos o levantamento webgráfico, das 15 reportagens, somente duas traziam casos de plantadoras. O cruzamento de contextos levanta indícios de que a prática de plantio de árvores possivelmente seja predominantemente masculina.

Os três colaboradores com idade superior a 60 anos são pessoas bastante conhecidas na cidade onde moram, reconhecidas como "plantadores" pela comunidade, e de origem rural. Todos apontam essa vivência "no sítio" como forte motivação para o plantio de árvores e a prática profissional como aperfeiçoadora do processo.

O plantador 2 é servidor público municipal e responsável pela manutenção da praça central da cidade, que revitalizou e onde faz os plantios. Nos contou ter morado em sítios durante a infância, e onde começou sua relação com as plantas. Após alguns anos, passou a trabalhar no viveiro de mudas municipal, se orgulhando pelo plantio várias árvores e matas da cidade, bem como a recuperação de áreas fora da mancha urbana. Ao analisarmos sua História Oral como um todo, sua motivação central parece ser advinda de sua curiosidade com a natureza, que foi aprimorada em seu trabalho, e com o passar dos anos, foi se tornando-se fruto de seus saberes, fazeres, sentimento de conexão e pertencimento com a natureza e seu amor pela cidade onde mora.

Ao falar da sua interação com esportistas que utilizam trilhas abertas por ele inicialmente para coleta e plantio de sementes, enfatiza a importância do "cuidado" com a natureza.

\begin{abstract}
De repente eu comecei a abrir um pedaço de trilha, que eu fazia trilha para coletagem de semente, semeação de sementes... Aí veio três motoqueiros e passou pela trilha e disse assim: "Ó Tonhão, podemos usar estas trilhas?". Eu falei: "Ó, meu amigo, é o seguinte, respeitando o meio ambiente não tem nada mais, pode conseguir passar". [...] Até hoje muitos motoqueiros vêm para Monte Alto para fazer as trilhas, e eu falei para eles, expliquei a eles sobre as toras, 0 que é meio ambiente, o que não é meio ambiente, respeito, respeito sobre a natureza, sobre as cobras, sobre os bichos, tudo... (Plantador 2)
\end{abstract}

O plantador 3 é muito conhecido por prática de enxertia em plantas, tendo sido vendedor de mudas e doces na feira do produtor, a maior feira livre da cidade. Aprendeu a técnica numa fazenda onde morava e trabalhava, e incorporou-a como prática profissional. Atrela sua motivação central para uma questão de ter curiosidade e admiração para com a natureza, como ilustra o excerto:

Curiosidade. Estava em contato com a natureza, eu sempre admirei muito a natureza, né. Então é isto aí... (Plantador 3)

O plantador 4 entrevistado é dos principais jardineiros da cidade de Monte Alto-SP, com mais de 25 anos de serviços. 
A jardinagem, atividade na qual faz também o plantio de árvores, foi incentivo de um amigo, mas veio depois do gosto pelas plantas. Então, eu gosto de mexer com as plantas. Eu gosto [do que faço]. [Me] Considero [plantador, porque] é o serviço da gente. A gente gosta. Tipo de jardinagem que a gente entende (Plantador 4)

Os três colaboradores com idade inferior a 60 anos têm perfis distintos e origem urbana. $\mathrm{O}$ plantador 1 é um jovem que relata plantar árvores desde criança. Conta que planta em sítios de amigos ou áreas de reserva ambiental. Sua principal motivação é o sentimento de conexão com a natureza. Os trechos extraídos da sua História Oral exemplificam esta constatação:

Eu sempre tive esse gosto pela natureza, eu não sei explicar ao certo, mas sempre gostei de apreciar as árvores, gosto de ver nascer, crescer, produzir, mas o certo, o porquê que eu gosto disso é difícil explicar. Foi desde pequeno, porque eu tive influência da minha avó, ela sempre gostou de flores, de plantas, e eu cresci perto dela, então eu fui influenciado por ela. Mas, de uns seis, sete anos eu já estava plantando também. (Plantador 1)

O plantador 5 é um jovem de 33 anos, líder da equipe do Ecopoint, grupo que joga um RPG online, que possui uma comunidade fictícia de cientistas que, entre outras coisas, faz pesquisas ambientais, pela qual foi inspiração para a fundação do Ecopoint. A equipe se mobiliza no Brasil todo para também levar a experiência do virtual para o real, plantando árvores em parques, praças e outras localidades.

Atrela sua motivação a um sentimento de conexão com a natureza. Afirma ter sido escoteiro e ter encontrado um modo de unir o engajamento dos jogadores virtuais em torno da causa do jogo, sua paixão com a natureza e fazer novos amigos na vida real. $O$ trecho abaixo exemplifica o que pensa este colaborador:

Não [foi de origem familiar], eu sempre tive uma conexão com a natureza. Não foi uma questão familiar não. Tanto que já fui escoteiro, já tive no meio do mato, sempre tive uma boa conexão com a natureza. Não foi ali não. Plantar coisa com meu pai não foi um catalisador disso. Eu não sei dizer qual foi o meu catalisador. Foi aquela conexão que quando você tá no lugar você se sente em paz, sabe? Eu sempre me senti assim. Eu sempre andei descalço no meio do mato pra sentir a terra, sempre fui assim. (Plantador 5)

O nosso sexto colaborador é um jovem plantador da cidade de Carapicuíba, identificado por meio de uma reportagem no levantamento webgráfico. Ele produz mudas de árvores nativas do Brasil em seu apartamento e também é fundador de uma comunidade sobre o tema no Facebook.

Não explicita sua motivação, mas contextualmente em sua História Oral, pensamos que sua motivação esteja atrelada à curiosidade e seu sentimento de conexão e amor à natureza, conforme trazem os excertos:

Eu achei uma sementinha na rua da casa da minha tia que eu estava indo passear com minha família, e eu achei várias sementinhas no chão, de uma espécie que 
hoje eu identifico como Sibipiruna, uma espécie brasileira, e eu plantei essa semente e germinou super fácil e eu pensei: "nossa que incrível, uma árvore miniatura dentro da minha casa!". Eu vi quão fácil era plantar. (Plantador 6)

Em nosso entendimento, pensamos que há fortes indícios de que a ligação emocional e conexão com a natureza é um fator importante, sendo mencionado por todos os colaboradores. A transmissão de conhecimentos pelos pais e avós foi apontada por um plantador, enquanto a maioria deles aponta que as técnicas e saberes adquiridos durante a prática são importantes para a criação de uma cultura de plantador.

Nos plantadores mais jovens, caso dos plantadores 1, 5 e 6, parece prevalecer a conexão e ligação com a natureza e o sentimento de utopia de querer melhorar o mundo onde vivem.

À medida que a idade aumenta, aumenta conjuntamente a importância dos saberes e fazeres ligados ao ato de plantar, caso dos plantadores 2, 3 e 4. Pensamos que isso se deva ao fato de os saberes populares serem frutos da imitação, da prática do dia a dia e da empiria, adquiridos quando esses plantadores moravam no campo.

\section{- Que saberes, técnicas e fazeres acionam?}

O plantador 1 ressalta que aciona conhecimentos aprendidos com o pai e a avó, reunindo em seus relatos saberes sobre vegetação, clima, que revelam conhecimentos científicos sobre o tema.

[A minha identificação com a natureza] é sim, muito forte. Acho que o princípio [da minha identificação] foi ela [referindo-se à avó]. Os primeiros passos foi ela para reconhecer as espécies, o jeito certo de plantar, para fazer o plantio da muda. Aí outras coisas nós vamos agregando conhecimento, vai pesquisando, vai passando um pro outro.

\section{[...]}

Procuro escolher, eu tenho esta visão de procurar plantar no tempo das águas, e na questão do solo, eu procuro sempre procurar espécie nativa, identificada no solo. Aqui é cerrado, a vegetação aqui é cerrado, então a gente foca mais nesta parte, das espécies do cerrado. (Plantador 1)

O segundo colaborador argumenta que sua infância em sítios foi importante, pois lá aprendeu sobre fazeres camponeses e saberes relacionados a tipos de planta e práticas de plantio, que culminaram na sua fase adulta tendo seu próprio sítio. A seguir, teve seus saberes aprimorados na prática, na empiria retirando sementes e fazendo mudas nos viveiros. Depois, pôde, a partir destas lentes, enxergar a importância da conservação das nascentes e serras. Logo após, pôs em prática seus saberes, traduzidos em fazeres na conservação e manutenção das praças municipais. Afirma que seus saberes foram obtidos em virtude do trabalho, o que em outras palavras apresenta indícios de que foi na prática e na empiria que ele obteve seus conhecimentos, como se nota no trecho a seguir: 
árvore que eu chegava para mim era um orgulho, uma semente tirada por mim. (Plantador 2)

O plantador 3 tem uma forte relação com a prática da enxertia, que é eminentemente uma prática popular que posteriormente foi sistematizada e interpretada cientificamente, estando fortemente permeada por conhecimentos da genética. Aponta que foi o seu trabalho que o levou a aprender as técnicas, aliado a sua curiosidade e motivação de estar constantemente mexendo na natureza, plantando e cultivando. Sente-se feliz em poder transmitir a outras pessoas que o procuram. Esta característica de transmissão de geração em geração é uma importante característica que demarca o saber popular.

Interessante que possui saberes que lhe permitem identificar quais plantas são oriundas de mudas de primeira geração e quais são enxertadas, o que é importante para a qualidade genética e para o próprio plantio de árvores, uma vez que plantas enxertadas não são passíveis de se reproduzirem, mas por outro lado, apresentam qualidades que a planta original não possui. Então o domínio de tais técnicas é importante para o entendimento da prática do plantio de árvores, embora ele não saiba explicar o porquê de uma planta enxertada não se reproduzir. Este fato é exemplificado abaixo:

Se plantar de semente não funciona. Daí eu não entendo o porquê.

(Plantador 3)

Ele também reconhece que há momento certo para plantar utilizando a técnica, ou seja, há um ciclo natural da planta a ser respeitado e observado.

O nosso quarto colaborador diz que a prática de seu trabalho em jardinagem requer técnica, sendo que não é qualquer um que o pode realizar. Além disso, argumenta ter aprendido na prática de seu trabalho. As técnicas vão além de saber manusear o maquinário peculiar à jardinagem, mas saber identificar um bom solo, época correta de se plantar, podar, cuidados e estética.

Ah, [para plantio] tem que esperar a chuva, tem que esperar a chuva. Porque tem vários tipos assim, que nem você vai plantar uma fruta, agora tem que esperar até lá para o fim de setembro.

$[\ldots]$

Ah, [sobre os solos] não é qualquer solo não. Tem solo que é bravo, plantou já morreu. Só se não cuidar legal mesmo, se não... Agora aqui é difícil morrer sabe? Porque a gente tá aqui, rega... Agora se é uma chácara que eu vou e volto daqui um mês para fazer o jardim, que o dono não pode ir lá, quando chega já era. Morre tudo. Não é qualquer um que mexe com isso. Tem que ter as manhas. Para podar, por exemplo, tem que saber, se não você estraga a planta. (Plantador 4)

O que notamos nesta descrição é que ele salienta com ênfase a importância das técnicas pautadas no empirismo que ele aprimorou após anos de trabalho e que hoje o permite fazer com muita perspicácia. 
O quinto entrevistado tem uma prática ligada à mobilização de ações de plantio, então não aciona saberes e fazeres do mesmo modo que os demais plantadores. De todo modo, merece o destaque a sua fala de que, embora as pessoas se interessem por integrar o grupo, se engajem com a causa, quando chega o momento de praticar, de exercer as técnicas inerentes ao processo de plantar (escavar, plantar, regar, etc), muitas pessoas acabam por desistir, pois envolve técnicas e manuseios próprios. Segundo o mesmo, para superar este eventual obstáculo é necessária boa vontade, tal como exemplifica o trecho a seguir:

Quando a gente fez, saímos em jornais no mundo todo, literalmente. Muitas pessoas se empolgaram, mas quando vão cavar buracos acabam desistindo da empolgação inicial. Por isso é necessário força de vontade. [A mobilização em torno da causa é o maior problema], mas não foi tão difícil assim quanto a gente imaginava. A comunidade está bem ativa. (Plantador 5 )

Por fim, nosso sexto colaborador apresenta uma gama enorme de saberes e fazeres ligados à sua prática de plantador. Primeiramente atrela que a maior parte de seus saberes são oriundos da prática, ou seja, dos fazeres. Esta é uma importante característica do saber popular, uma vez que é na prática do trabalho e na imitação que ele é aprendido.

[Aprendo] na prática principalmente. Eu por ser um paisagista, eu tenho que fazer testes né, eu tenho que ver o que realmente funciona. Não posso simplesmente pegar uma coisa da internet e falar: "Oh, é assim, assim e assim". Eu gosto mesmo é de ver se aquilo realmente funciona porque cada local é uma coisa, cada local funciona de um jeito diferente. Se na internet tá dizendo: "Ah, precisa de mais água, alguma coisa. Você tem que colocar água na planta a cada, a cada três dias". Eu vou lá e faço isso e encharco a planta porque tem a questão do vaso que eu estou usando, se a minha região tem um clima quente ou frio, então isso depende muito, sabe? Tem que ser avaliado tudo isso. Então eu acabo aprendendo mais na prática né. Eu pego a planta e faço testes, tomando experiências né, não só conhecimentos, mas experiências. Mas a internet super me ajuda também. (Plantador 6)

Ele relata conhecimentos diversos relacionados a clima, solo, $\mathrm{pH}$, fases da Lua, entre outros. Embora a prática seja enfatizada, o cabedal de conhecimentos científicos está fortemente presente, conforme exemplificado a seguir.

Tudo, [eu] avalio tudo. O solo, o que vai precisar no solo, faço testes de $\mathrm{pH}$. Plantas nativas. Elas têm condições próprias, o nosso solo, o solo brasileiro é naturalmente, levemente ácido. Eu não posso colocar uma planta nativa em um solo alcalino. Tem tudo isso para avaliar. Então, se o solo está muito ácido eu uso, acabo usando cal, cálcio já pronto para uso e eu faço o método de lançamento. Eu tenho um pouco de prática, então eu só jogo. Não sei explicar, não vou saber explicar, mas é o método de lançamento mesmo. (Plantador 6) 
Não é possível caracterizar isoladamente qual saber é peculiar aos plantadores, pois o que vemos é a hibridização em essência. Ora acionam saberes mais empíricos, ora saberes mais científicos. Isso, pensamos poder ser explicado por Fleck (2010), quando ele diz que os saberes populares são mais dotados pela acumulação, experiência e imitação, mas pode ser também resultado da popularização de saberes científicos. Quando os plantadores leem alguma matéria com teor científico, seja na internet ou veja na TV, podem vir a se interessar e investigar mais sobre o assunto, tal como o plantador 6 que afirma ler sobre várias técnicas e conhecimentos e testá-los nos próximos plantios. Por nenhum deles ser formado em uma área acadêmica que os tornem pesquisador na área, o que vemos é que a prática e a empiria é o que subsidia seus conhecimentos.

Percebemos aqui um resultado similar ao obtido no levantamento webgráfico, em que o diálogo de saberes era apontado como um fator importante nas práticas descritas em reportagens disponíveis na grande mídia.

\section{- Onde plantam?}

Esse aspecto se refere àqueles pressupostos trazidos por Leff (2009a, b, 2010a, b, 2011, 2015) que traduzem o sentimento de pertencimento e conexão com a natureza como sendo um complexo resultado da integração do ser humano na natureza, tendo um território, saberes e culturas inseridos e respeitados em sua diversidade, trazendo um sentimento de completude, realização e felicidade.

Os plantadores entrevistados apontam que possuem sentimentos variados de inclusão e pertencimento à natureza, querendo melhorar o espaço onde vivem.

Assim como apontado em Leff (2015), parece haver uma relação de habitat, em que os nossos colaboradores interagem culturalmente com o ambiente em que vivem, buscando alterar positivamente o seu meio. A identidade criada por eles no espaço em que vivem é central para a indicação de onde plantam.

O plantador 1 aponta possuir grande sentimento de conexão com a natureza, que o faz querer plantar, ver as plantas nascerem e crescerem. Costuma plantar em áreas de reserva da cidade, bem como em sítios de amigos:

Quanto a mim, geralmente eu mesmo plantava no sítio em áreas de reserva, que nós pegamos mais área de reserva, são sítios dos meus amigos. (Plantador 1)

O que se nota é que sua prática parece ser regionalizada, sendo na sua cidade, bem como em sítios de amigos próximos, locais de proximidade de certo modo afetiva, onde sente prazer em estar e pode acompanhar o crescimento das plantas.

O plantador 2, além de destacar as áreas da cidade em que efetuou plantios em razão da sua atuação profissional, ressalta o impacto das sementes que plantou, bem como mudas que produziu e que foram plantadas por outras pessoas em vários locais da região onde mora. 
quanto é lado... Pivetta, vários lugares nós servíamos mudas, Cestari também pegaram muitas mudas nossas lá, entrava bem dizer em parceria, sabe? Às vezes pegava um balainho e trocava sobre muda na prefeitura e daí começava plantio.

[...]

O nosso Turvo [o rio Turvo é um rio que possui nascente em Monte Alto] aqui embaixo, abaixo do museu nós tivemos muitas mudas, onde plantamos, ainda até o tratorzinho tá carregado de mudas, a carretinha tá lá em casa, em casa tenho um retrato que tava tirando, plantando as mudas lá abaixo do museu. (Plantador 2)

A partir destes trechos, levantamos novamente indícios de que exista uma forte relação entre o local que planta, no caso deste plantador é na cidade que diz amar, com sua cultura, simbolizando a sensação de pertencimento.

O terceiro plantador, por sua vez, parece ser influenciado fortemente por uma rica e complexa relação entre saberes e fazeres e sentimento de pertencimento. Inicialmente, ele plantava em sítios da família, bem como em sítios vizinhos onde era empregado. Atualmente, tem no seu quintal o local de suas práticas de plantio. Novamente se denota que há uma relação fortemente intricada entre local e práticas.

O quarto plantador demonstra gostar da natureza, do seu trabalho, e ao que nos parece, gera-se um sentimento de conexão inerente. No que tange ao local que planta, normalmente é nas chácaras, sítios e casas onde é contratado, mas na sua casa também exercita seus plantios.

Em casa eu tenho abacate, tem tamarindo, tem graviola, tem mais na calçada e na rua, entendeu? Tem bastante coisa lá. Tem banana, essas coisas. Assim olha, [na] frente que não foi feita calçada ainda, lá tem limão, abacate, tinha graviola, tinha uns 4 ou 5 tipos de frutas, mas quando for fazer a calçada tem que arrancar. Aí deixa só essas arvorezinhas que tem na rua. (Plantador 4)

Oquinto colaborador demonstra o sentimento de conexão e pertencimento em diversos momentos em sua História Oral, inclusive explicitamente na sua motivação central. Entretanto, selecionamos este trecho que é interessante por envolver e sintetizar seu projeto inicialmente ambicioso, mas que deu resultados importantes, que era de unir jogadores em torno de uma causa nobre que é a ambiental, a qual o plantador sempre pareceu se mover por ela, além de formar laços mais profundos de amizade, para além das telas de computador.

Queria unir os jogadores, queria ajudar a melhorar o meio ambiente, queria ajudar a melhorar o local onde a gente vive e melhorar a sociedade e criar laços, que é o que falta, a gente conversa com as pessoas, mas falta criar laços na vida real, sabe? E à medida que você começa conversar com a pessoa e você encontrar a pessoa na vida real parece que quebra um pouco esta magia: normalmente as pessoas ficam acanhadas, tipo, não é mesma coisa. A minha ideia era trabalhar lado a lado com esta pessoa no sol quente, cavando buraco, plantando negócio para causar um impacto no futuro. Então tem toda essa simbologia de você começar um negócio novo que vai dar frutos lá na frente. (Plantador 5) 
Examinemos o trecho abaixo, em que após uma prática localizada e regional, a ideia toma proporções globais, inspirando pessoas ao redor do planeta:

Isso cresceu muito hoje em dia. Inicialmente era uns 13, eu sou o fundador, mas quem participou do evento lá em Sorocaba, do piloto, foram 13 pessoas. Agora, no Brasil, nós devemos estar por volta de 200 a 300 pessoas. No México também deve estar por aí. Tem um grupo sendo fundado nos EUA, na Inglaterra, na Tailândia e acho que na França também. (Plantador 5)

Este plantador começou com uma prática localizada e regional, mas que ganhou proporções, atingindo a escala global. Isso é, tem várias escalas reconhecidas, não apenas uma em detrimento a todas as outras.

No próximo trecho, ele diz algo que corrobora com tudo que reunimos até aqui sobre pertencimento: querer melhorar um local, empenhando técnicas e boa vontade. A seguir ele demonstra todo seu sentimento utópico de melhoria do local onde vive:

Acho que para a gente existir bem, a gente tem que causar mudanças aonde a gente vive. As mudanças têm que ser boas, têm que ser positivas, e não existe mudança melhor que começar a reparar os danos que a gente causou na natureza. (Plantador 5)

O sexto plantador também apresenta como fator importante a questão da conexão e do pertencimento. Como vemos no excerto a seguir, ele se diz sentir muito bem em contato com a natureza e também elege como um disparador de sua prática de plantio de árvores nativas ter descoberto que em sua cidade, antes do advento da urbanização, havia uma floresta nativa. Há indícios, portanto, que ele tenha um sentimento de resgate da qualidade de vida, de querer melhorar o local onde vive.

A natureza me cativa. Eu paro para observar as coisas da natureza e se eu ficar, eu fico horas assim. Porque são muitos detalhes e cada coisinha eu vejo que tem um motivo para existir. E você planta uma semente e no outro dia você olha e tem algo diferente: cresceu uma raiz, a semente estourou para começar a inchar e crescer a raiz, aí no outro dia já tem uma folhinha nascendo, depois tem mais folhas, depois já criou um caule, vários galhos, é incrivel assim... Eu sou fascinado pela natureza e pela arte. Então eu acabei encontrando o paisagismo e acabo implantando espécies nativas nesses lugares. Tudo nela me atrai! $O$ fato de eu estar dentro de uma floresta já me deixa alegre, sabe? Porque é um ambiente totalmente diferente do que a gente tem aqui na cidade. As pessoas acabam esquecendo assim é... [pensa um pouco] a conservação do meio ambiente. O quão importante é cada floresta, o quão importante é cada árvore, o quão importante é cada bichinho. Porque se você destrói algo, aquele algo vai fazer falta para outra coisa e assim por diante. É um ciclo, né. Se eu destruo algo, se eu destruo uma espécie, aquela espécie vai fazer falta para outra espécie. É uma cadeia né. É um ciclo. Então a gente tem que se ligar para a conservação do meio ambiente.

[...]

Com certeza [quero melhorar onde moro]! Porque se eu não vejo floresta aqui é porque ela está fazendo falta. Aqui existia uma floresta, eu estou no meio de 
uma floresta urbana que foi destruída, mas ela existiu. Então eu quero trazer isso de volta, trazer com isso as espécies da fauna nativa também atraídas pelas árvores e espécimes vegetais, porque além de tudo, embeleza a cidade e eu acho que assim, as pessoas acham que não podem plantar por falta de espaço, mas eu plantei 800 mudas nativas dentro do meu apartamento de $50 \mathrm{~m}^{2}$, então é só querer, só força de vontade mesmo. (Plantador 6)

Ao fim, o fato de o plantador plantar suas mudas a partir de sementes dentro de sua casa, um apartamento, aliado a todo sentimento utópico de recuperação das áreas florestais da sua cidade, é sugestivo de tudo o que falamos até aqui sobre pertencimento. Por fim, outro espaço de plantio dele é no seu condomínio, para qual obteve aprovação da síndica. Ainda como profissional do paisagismo, realiza plantios em casas de outras pessoas que requisitam seu trabalho na sua cidade.

O que notamos, em resumo, é que há indícios de que os plantadores possuem fortemente o sentimento de pertencimento. São atores que, pela identidade criada com um habitat, se lançam a melhorá-lo. Suas atividades são localizadas, para qual acionam dos mais diversos saberes e fazeres. Mais que um local, os plantadores parecem desenvolver um pertencimento com a causa de plantar, pois, talvez se se mudassem de cidade, continuariam a plantar, alterando seu novo habitat.

Os mais experientes tiveram suas iniciações motivadas inicialmente pelo trabalho, da vida no campo que se originaram, mas acabaram por tomar a prática por hobby, plantando nas suas casas, nos bairros, por toda cidade e se orgulham das paisagens que modificaram. Os mais jovens são movidos pela utopia, seja de recuperar ecossistemas, até a mobilizar as pessoas em torno da causa.

Tais dados também corroboram com o levantamento webgráfico, em que o sentimento de pertencimento também se mostrava como um dos temas centrais das motivações expressas em reportagens disponíveis na grande mídia.

\section{Considerações Finais}

Mobilizados pela perspectiva de uma racionalidade ambiental, voltamos nosso olhar para práticas de protagonismo ambiental relacionadas à arborização, buscando investigar as motivações envolvidas em práticas de arborização promovidas por atores sociais em diferentes espaços.

Nosso questionamento sobre a relação entre as ações de plantadores e a vinculação a uma racionalidade ambiental caminham para uma aproximação positiva. A racionalidade ambiental está pautada em plurais de saberes e fazeres e no sentimento de pertencimento.

Percebemos que, ao perfilarmosos plantadores eas práticas, hárico diálogo entre saberes. Aspessoas se sentem realizadas e satisfeitas ao plantarem, algo que está para além da satisfação exclusivamente material. Ao plantarem, observam temporalidades diferentes daquela que atrela o tempo à produtividade lucrativa, ou ainda, que veria o tempo útil apenas àquele que gera desenvolvimento e progresso. Ao observarem os ciclos naturais, os plantadores dão mostras à pluralidade de visões e percepções.

A prática é diversa em escalas, porém todas são marcadas por indícios de que o pertencimento é quesito importante. Algumas vezes, árvores são plantadas por meio de ações de setores sociais diversos e acabam não resistindo por não ter ninguém que ofereça cuidados às árvores plantadas, um exemplo 
notório de que a identificação e o pertencimento são importantes para a conservação e para tais práticas.

Há indícios, de acordo com os principais resultados, que haja relação entre a motivação central dos plantadores e sua causa de plantar com a temática do pertencimento e que o entendimento das relações entre saberes e fazeres parece ser importante neste processo. Tais apontamentos sinalizam que a pluralidade de saberes, fazeres, culturas e ópticas estão presentes, abrindo espaço para discussão sobre uma racionalidade ambiental envolvida.

\section{Agradecimentos}

Agradecemos à Coordenação de Aperfeiçoamento de Pessoal de Ensino Superior (CAPES) e ao Conselho Nacional de Desenvolvimento Científico e Tecnológico (CNPq) pelo fomento à pesquisa.

\section{Referências}

ALBERTI, V. Manual de História Oral. 2. ed. Rio de Janeiro: Editora Fundação Getulio Vargas, 2004. FLECK, L. Gênese e desenvolvimento de um fato científico. Belo Horizonte: Fabrefactum, 2010. GARNICA, A. V. M. ¿Cómo se puede implementar la historia oral en lá educación matemática? Revista Educación y Pedagogía, v. 23, n. 59, p. 67-83, 2011.

LEFF, E. Ecologia, capital e cultura: a territorialização da racionalidade ambiental. Petrópolis: Editora Vozes, 2009a.

LEFF, E. Complexidade, racionalidade ambiental e diálogo de saberes. Educação \& realidade, v. 34, n. 3, p. 17-24, 2009b.

LEFF, E. Discursos sustentáveis. São Paulo: Cortez, 2010a.

LEFF, E. Pensar a complexidade ambiental. In: LEFF, E (Coor.). A complexidade ambiental. 2. ed. São Paulo: Cortez, 2010b.

LEFF, E. Complexidade, interdisciplinaridade e saber ambiental. Revista Olhar de Professor, v. 14, n. 2, p. 309-335, 2011.

LEFF, E. Saber Ambiental: sustentabilidade racionalidade, complexidade, poder. 11. ed. Petrópolis, RJ: Vozes, 2015.

NASCIBEM, F. G. Protagonismo ambiental em práticas de arborização: elementos motivacionais, saberes e fazeres de atores sociais. 2019. 154 p. Dissertação (Mestrado em Ensino de Ciências e Matemática) - Instituto de Física Gleb Wataghin, Universidade Estadual de Campinas, Campinas, SP, 2019.

NASCIBEM, F. G.; VIVEIRO, A. A.; GONCALVES JUNIOR, O. Elementos motivacionais, saberes e práticas relacionadas ao plantio de árvores em ações de protagonismo ambiental: uma revisão bibliográfica. Revista Ciências em Foco, v. 10, p. 64-71, 2017. 
VIVEIRO, A. A.; GONCALVES JUNIOR, O. Mapeamento de iniciativas de protagonismo ambiental e fomento à rede de plantadores de árvores. Educação Ambiental em Ação, n. 58, online, dez. 2016/ fev. 2017. Disponível em: http://www.revistaea.org/artigo.php?idartigo=2542. Acesso em: 3 mar. 2020.

\section{Fabio Gabriel Nascibem}

É Licenciado em Química pelo Instituto de Química de Araraquara - UNESP. Atuou em vários projetos de extensão, entre eles o projeto «Ciência vai à escola» vinculado ao Centro de Ciências de Araraquara. No âmbito de pesquisa, pesquisou na área da natureza da ciência e atualmente pesquisa saberes populares e o diálogo com o conhecimento científico. É membro do Grupo de Estudos, Pesquisas e Práticas Pedagógicas em Ensino de Ciências e Educação Ambiental, sediado na Faculdade de Ciências e Letras de Araraquara - UNESP, sob liderança da Profa. Dra. Maria Cristina de Senzi Zancul e da Profa. Dra. Alessandra Aparecida Viveiro. Também é membro do Grupo FORMAR-Ciências, sediado na UNICAMP. Se interessa por Ensino de Ciências e Educação Ambiental. É mestre em Ensino de Ciências e Matemática, pelo Programa Multiunidades em Ensino de Ciências e Matemática - UNICAMP. Atualmente é doutorando em Ensino de Ciências e Matemática pelo Programa de Pós-graduação Multiunidades em Ensino de Ciências e Matemática (PECIM), da Universidade Estadual de Campinas - UNICAMP. Foi professor de Matemática, Química e de Física na rede pública e particular. Atualmente atua na docência em nível superior, em cursos de graduação em Ciências Biológicas, como bolsista de estágio de docência junto à UNESP e participa do Programa de Estágio Docente (PED) na Faculdade de Educação da Unicamp junto ao Curso de Pedagogia. E-mail: fnascibem@yahoo.com.br ORCID: https://orcid.org/0000-0002-6465-0980

\section{Alessandra Aparecida Viveiro}

Professora, doutora na Faculdade de Educação da Unicamp. Docente do Programa de Pós-Graduação Multiunidades em Ensino de Ciências e Matemática (PECIM) - Unicamp. Líder do Grupo de Estudos e Pesquisas sobre Formação de Professores e Práticas Pedagógicas em Ensino de Ciências e Educação Ambiental - ECiEA (Unesp/Unicamp) e do Grupo FORMAR-Ciências (Unicamp). Possui graduação em Licenciatura em Ciências Exatas pela USP, mestrado e doutorado em Educação para a Ciência pela UNESP. Possui experiência como docente na Educação Básica. Na Educação Superior, atuou junto à UFSCar, UnB e UNESP. Desenvolve projetos de pesquisa e extensão em Ensino de Ciências e Educação Ambiental. E-mail: alessandraviveiro@gmail.com

ORCID: https://orcid.org/0000-0002-3175-7132

\section{Oswaldo Gonçalves Junior}

Pós-doutorando na Columbia University (The Institute of Latin American Studies - ILAS). Professor Doutor da Faculdade de Ciências Aplicadas (FCA-UNICAMP), no curso Bacharelado em Administração Pública. Professor Pleno no Mestrado Interdisciplinar em Ciências Humanas e Sociais Aplicadas (ICHSA). Doutor em Administração Pública e Governo (EAESP-FGV), Mestre em Educação (FEUSP), Bacharel e Licenciado em História (FFLCH-USP). Possui experiência como docente na Educação Básica e na Educação Superior. Atuou em diversas organizações como especialista e gestor. Como pesquisador, tem especial interesse pelos seguintes temas: Administração Pública; Burocracia; Análise 
e Avaliação de Políticas Públicas; Sociologia Econômica; Tecnologia da Informação; Gestão e Mudança Organizacional; Novos arranjos institucionais; Ciências Sociais Aplicadas em perspectiva com Políticas Públicas; Ambiente, Educação e Desenvolvimento. E-mail: osgoju@gmail.com

ORCID: https://orcid.org/0000-0002-3033-3741 